\title{
Histological Hashimoto's disease in a benign cystic ovarian teratoma
}

\author{
ALAN A. WATSON \\ From the Department of Pathology, University of Cambridge, Tennis Court Road, Cambridge
}

SYNOPSIS A case of Hashimoto's disease of the thyroid component of a benign cystic ovarian teratoma is reported, unassociated with previous neck surgery. Three hundred and fifteen cases of ovarian teratomata were reviewed to determine the incidence of this complication.

Whilst the histological features of several disorders may be discovered in ovarian teratomatous thyroid tissue, a notable exception is that of autoallergic chronic thyroiditis, Hashimoto's disease.

In 1965 Erez, Richart, and Shettles reported the first case of chronic thyroiditis in a benign cystic teratoma of the ovary, discovered seven years after a subtotal thyroidectomy for non-specific chronic thyroiditis.

This is a further case of Hashimoto's disease in a benign cystic ovarian teratoma and is probably the first reported without either previous surgery to the thyroid gland or clinical thyroid disease. Furthermore, 315 cases of benign cystic ovarian teratoma have been reviewed in order to examine the incidence and nature of any included thyroid tissue.

\section{Case Report}

J. B., a woman, aged 31 years, complained of primary infertility; for this she received endometrial curettage. Two years later she underwent myomectomy, shortening of the round ligaments, and a Gillian's ventrisuspension. During the next 10 years she complained of menorrhagia, for which an abdominal hysterectomy was performed. Apart from being slightly overweight, she had no other complaints. At the time of the operation, the left ovary was cystic, $7 \mathrm{~cm}$ in diameter, and firmly adherent within the pouch of Douglas. The normal right ovary was preserved after division of many adhesions. An uneventful recovery followed.

\section{Macroscopic Examination}

The specimen consisted of a uterus and cervix Received for publication 28 July 1971
$(8.0 \times 6.0 \times 5.5 \mathrm{~cm})$ with an attached thin left Fallopian tube $5 \mathrm{~cm}$ in length and an irregular cystic left ovary (maximum diameter $7 \mathrm{~cm}$ ). On serial slicing the ovary showed yellow sebaceous material, hair, and a thickened, glistening cyst wall. An irregular pink-white $1.5 \mathrm{~cm}$ ovoid mass was present at one pole within the cyst. The myometrium, endometrium, endocervix, and Fallopian tube appeared unremarkable.

\section{Histological Examination}

The cyst wall was composed of loose fibrous connective tissue lined by keratinizing squamous epithelium, ciliated columnar epithelium, and flattened or cuboidal epithelium. Cartilage, hair, smooth muscle, and salivary gland tissue were also present.

One area contained thyroid tissue, consisting of well filled acini lined by flattened epithelium and areas of Askanazy cells forming small, colloid-filled acini or solid-type acini (Fig. 1). The peri-acinar tissues contained mature lymphocytes, lymphoid follicles, and enlarged reactive centres (Fig. 2). The appearances were consistent with the chronic lymphocytic thyroiditis of Hashimoto's disease. Lymphocytic infiltration was not seen in association with any of the other teratomatous elements.

\section{Serological Investigations}

The following postoperative investigations of the functional state of the thyroid showed: latex test negative, tanned red cell titre 1:250; thyroid precipitation test negative; antinuclear factor negative; and serum cholesterol $155 \mathrm{mg} / 100 \mathrm{ml}$. 


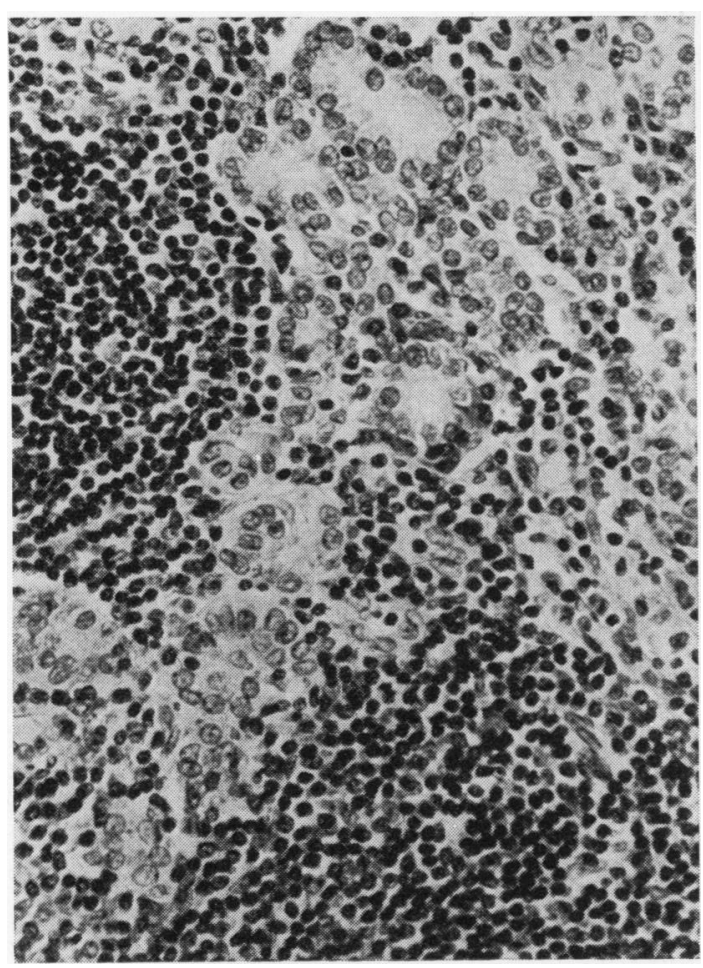

Fig. 1 Ovarian thyroid tissue showing Askanazy cell formation and an intense lymphocytic infiltration ( $H$ and $E \times 125$ ).

\section{Discussion}

Hashimoto's disease may be seen as discrete foci of intense lymphocytic infiltration or as large, widespread confluent areas accompanied by lymphoid follicles with reactive centres and characteristic cytological acinar changes.

That such changes are not seen more often in ectopic thyroid tissue remains inexplicable. Erez, Richart, and Shettles (1965) were unable to find in the English literature any case of chronic thyroiditis in a benign cystic ovarian teratoma. In their case, the patient had undergone a partial thyroidectomy for chronic thyroiditis. Hashimoto's disease was not mentioned in the report. The patient was later found to have bilateral benign cystic ovarian teratomas. In the ovarian thyroid tissue, chronic thyroiditis was found consistent with Hashimoto's disease. Postoperative tests of thyroid antibody activity were negative.

In the present case, there was no surgical interference with the thyroid and an external examination was normal. There had been, however, a previous internal gynaecological manipulation and it is possible that some trauma, albeit rather limited, might have initiated the formation of the ovarian Hashimoto's disease.

Immunological investigations have failed to demonstrate the presence of any thyroid-component antibodies one year after operation.

Autoallergic haemolytic anaemia described by

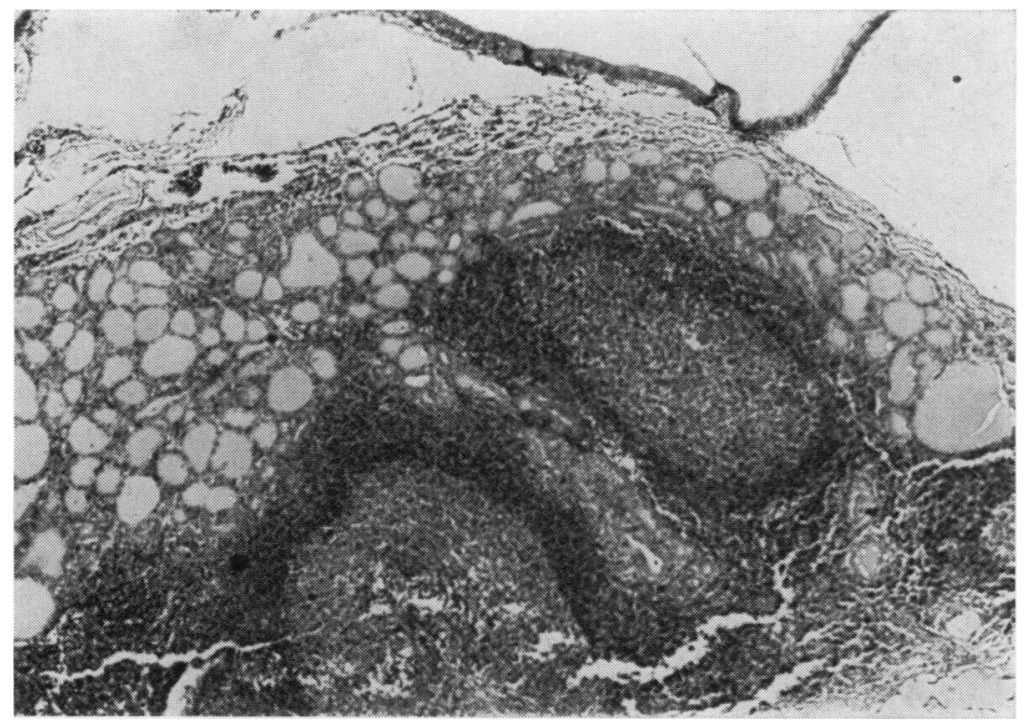

Fig. 2 Ovarian thyroid tissue with prominent lymphoid follicles and histological Hashimoto's disease $(H$ and $E \times 16)$. 
Barry and Crosby (1957) in a single case was cured by removal of a benign ovarian teratoma. They have found reports of nine other cases with a similar association between autoallergic haemolytic anaemia and a benign teratoma believing that, in these cases, the formation of red cell autoallergic antibodies appears to be related in some way to the presence of a neoplasm. This was also discussed as a possible mode of development of autoimmunization by Dameshek, Schwartz, and Oliner (1961). In this present case an autoallergic haemolytic anaemia was not found.

Caruso, Marsh, Minkowitz, and Karten (1971) have reviewed 305 teratomas of the ovary and discovered that thyroid tissue was present in only 20 cases $(7 \%)$ and struma ovarii in two cases $(0.7 \%)$. There is no mention of Hashimoto's disease in connexion with any of their cases. I have reviewed 315 cases of ovarian teratomas from the surgical material of the Addenbrooke's Hospital, Cambridge, and found 17 cases containing thyroid tissue $(5 \%)$ and struma ovarii in five cases $(1.5 \%)$. The teratoma with the Hashimoto's disease is included in the 17 cases.

I wish to record my appreciation to Dr G. A. Gresham for advice and encouragement, to Miss J. E. Bottomley for the use of the clinical records, and to Miss K. M. Farrer of the University Department of Medical Photography for the illustrations.

\section{References}

Barry, K. G., and Crosby, W. H. (1957). Auto-immune hemolytic anemia arrested by removal of an ovarian teratoma: review of the literature and report of a case. Ann. intern. Med., 47, 10021007.

Caruso, P. A., Marsh, M. R., Minkowitz, S., and Karten, G. (1971). An intense clinicopathologic study of 305 teratomas of the ovary. Cancer (Philad.), 27, 343-349.

Damashek, W., Schwartz, R., and Oliner, H. (1961). Current concepts of autoimmunization: an interpretive review. Blood, 17, 775-783

Erez, S. E., Richart, R. M., and Shettles, L. B. (1965). Hashimoto's disease in a benign cystic teratoma of the ovary. Amer. $J$. Obstet. Gynec., 92, 273-274. 